\title{
Streaming musical en Spotify: ubicuidad entre géneros y estados de ánimo
}

JIMENA JÁUREGUI, UBACYT -UNIVERSIDAD DE BUENOS AIRES, ARGENTINA

RESUMEN: A partirdeladigitalizaciónylaemergenciade Internet, laindustria dela música atraviesa un proceso de transformación entre el modelo broadcasting y el networking. En los últimos años, los servicios de streaming presentan un crecimiento sostenido como forma de acceso y reproducción musical frente al formato físico y a las prácticas de descargas digitales. Spotify se destaca entre las aplicaciones basadas en opciones gratuitas con publicidad o de pago por suscripción que ofrecen musicalizar en todo momento, en cualquier lugar.

Ubicuidad y movilidad se anuncian como efectos novedosos del cambio tecnológico. Sin embargo, el estado actual de la mediatización musical requiere ser indagado en su correlato histórico en tanto articulación especifica de dispositivos técnicos, discursos y prácticas sociales. Entre la música funcional y los géneros consagrados previamente por la industria discográfica, la clasificación de una oferta múltiple propone un modo de escucha como acompañamiento de la actividad social.

PALABRASCLAVE: streaming, ubicuidad, movilidad, géneros, Muzak.

ABSTRACT: From digitalization and Internetemergency, the musicindustrygoes through a transformation process from a broadcasting model to networking. In the last years, streaming services show a sustained growth as a way of access and music reproduction instead of physical format and digital downloading practices. Spotify stands out among applications based on free options with advertising or on paid subscriptions, which offer music for every moment, everywhere.

Ubiquity and mobility are advertised as novel effects of technological change. However, the current state of recorded music requires to be inquired in its historical trajectory as a specific articulation of technical devices, discourses and social practices. Among functional music and genres previously established by discographic industry, the classification of a multiple offer proposes a way of listening as accompaniment to social activity.

KEYWORDS: streaming, ubiquity, mobility, genres, Muzak. 


\section{INTRODUCCIÓN}

Desde la década de 1990, la industria musical atraviesa un proceso de transformación impulsado por la digitalización y el desarrollo de Internet. Su basamento en la producción de discos físicos fue embestido por la emergencia de formatos de compresión de audio como el MP3 y la consolidación de su uso social en las prácticas de descargas. En los últimos años, luego de un período de crisis y reestructuración, las plataformas que ofrecen servicios de streaming gratuitos o de pago por suscripción para la escucha instantánea en cualquier momento y lugar anuncian la reconversión hacia un modelo sostenido en la música digital ${ }^{1}$.

Estas tendencias fueron relevadas en el informe anual de la Federación Internacional de la Industria Fonográfica (IFPI, 2015). Con proyecciones auspiciosas, la institución que nuclea a 1300 compañías discográficas sostiene que en el año 2014 el aumento general del streaming, especialmente de las suscripciones, en un $39 \%$ constituye el principal indicio del avance hacia un crecimiento sostenible. Los efectos de este impulso quedaron evidenciados, por primera vez en la historia, en la equiparación de los ingresos percibidos por las ventas digitales y por las ventas físicas ${ }^{2}$.

Entrelas opciones que presentan mayor discografía yalcance internacional para la reproducción legal de música en línea se destaca Spotify ${ }^{3}$. Desde sus primeros desarrollos en 2006, la compañía fundada en Estocolmo por Daniel Ek y Martin Lorentzon ha superado en 2015 los 30 millones de canciones con alcance en 58 países. En sus versiones de reproductor web, aplicación de escritorio o mobile para tablets y smartphones, cuenta tanto con la modalidad de acceso gratuito con publicidad como con la "Premium" de pago.

1 Este trabajo se inscribe en el marco del proyecto con subsidios de la Secretaría de Ciencia y Técnica de la UBA (UBACyT) Letra, imagen, sonido. Convergencias y divergencias teóricas y metodológicas entre medios y espacio urbano. FSOC-UBA.

2 Los ingresos mundiales de la industria por ventas digitales aumentaron un 6,9\% en 2014 e igualaron a las ventas en formato físico en un $46 \%$. Los servicios por suscripción fueron los principales impulsores tras mantener una tendencia al alza con el 23\% del total de ventas digitales a nivel mundial (IFPI, 2005).

3 Entre otras aplicaciones musicales de streaming por suscripción no analizadas en esta oportunidad se destacan Apple Music, Deezer, Google Play, Radio, Rhapsody, Tidal y YouTube Key Music. 
En esta transición de la industria fonográfica, Spotify se despliega como un espacio clave de indagación sobre los cambios producidos en la mediatización musical. Las dificultades de aprehensión de un objeto novedoso y en vertiginoso movimiento exigen atender a las problemáticas del surgimiento de los fenómenos mediáticosylos modos de producción dela novedad discursiva. En ese marco, partiremos de la periodización histórica del vínculo entre músicas y medios, para luego describir cómo se articulan las series de los dispositivos técnicos, los géneros y estilos discursivos y las prácticas sociales implicadas. El objetivo de este modelo semiohistórico (Fernández, 2008a) es reconocer cuáles rasgos resultan novedosos, exentos de la mirada tecnológica determinista y de la homologación de fenómenos que responden a distintas temporalidades mediáticas.

\section{STREAMING MUSICAL EN EL POSTBROADCASTING}

En referencia a una corriente que fluye sin interrupción, el streaming puede ser definido como la distribución digital de archivos multimedia a través de la difusión continua por una red informática. El usuario recibe y reproduce audio y/o video al mismo tiempo en que estos son distribuidos por un proveedor, sin necesidad de completar la descarga. Si bien sus orígenes en Internet datan de mediados de los años 90, el despliegue de las plataformas musicales basadas en servicios de streaming se desarrolló luego de una década, con la ampliación del ancho de banda, las conexiones wi-fiy el uso de smartphones en el entornoglobal.

El proyecto inicial de Spotify fue creado en Suecia en 2006 pero se lanzó oficialmente el 7 de octubre de 2008 al acordar licencias con las grandes compañías discográficas tras dos años en versión de prueba. Junto a la apertura de los servicios de pago, las cuentas gratuitas limitadas por invitación fueron extendidas gradualmente llegando en 2009 al Reino Unido. Luego de diversos obstáculos, que incluyeron el haber sido bloqueado en millones de computadoras al ser identificado como un troyano por el antivirus Symantec, hacia 2011 Spotify logró asentar sus bases con el lanzamiento en Estados Unidos y el abandono del modelo parcial peer to peer (red entre pares).

Este proceso de adecuación del streaming en Spotify, que continuaría generando distintas controversias, manifestó las tensiones vigentes entre la industria fonográfica, fundada bajo un sistema centralizado de producción y distribución, y las lógicas de la comunicación en red propiciadas por Internet. En correspondencia con las transformaciones operadas sobre el conjunto delos medios masivos, José Luis Fernández (2014) distingue ambas configuraciones como aquellas propias del período sostenido bajo el modelo broadcastingfrente al advenimiento del networking. Su diferenciación en la historia de la música en grabado responde a etapas específicas de la industria y concretamente a los modos del contacto entre los intérpretes y sus públicos. 
El broadcasting comprende situaciones comunicacionales en cuyo marco los sistemas de intercambio discursivo implican a pocos emisores para muchos receptores. Bajo esta lógica se desarrolló la industria musical en las primeras décadas del siglo XX, a partir de la construcción del sistema de medios sonoro y su despliegue audiovisual. El networking, en cambio, responde al esquema reticular muchos-a-muchos y sus dinámicas en relación a la música parten de las posibilidades de digitalización, de las descargas, el intercambio peer to peer y la expansión de los sitios musicales.

El impacto de las transformaciones entre un modelo y otro fue ponderado desde distintas perspectivas que identificaron el aumento de las descargas digitales como la causa de la desmaterialización de la música ${ }^{4} \mathrm{o}$ a la innovación tecnológica como desencadenante de cambios operados sobre la experiencia sensorial y perceptiva. Desde esta última posición, George Yúdice sostiene que la música se presenta cada vez más ubicua ya que no hay espacio donde no se la oiga:

Desde el acompañamiento musical en el cine, que data de antes del desarrollo de las talkies, hasta los iPods de hoy, pasando por la "muzakificación" de ascensores y shoppings y la incorporación de chips sonoros a las tarjetas de cumpleaños y navidad, o la música a la que nos someten mientras aguardamos en el teléfono para que nos atiendan los que prestan servicios al cliente, nuestro paisaje acústico, asistido tecnológicamente, resuena cada vez más, permeando nuestra experiencia (2007, p.18).

El streaming, muy presente en las investigaciones en la actualidad, vendría a profundizar y complejizar esta tendencia. Boschi, Kassabian y García Quiñones (2013) describen un día en la vida de un ciudadano promedio como oyente de música ubicua y, entre otras situaciones, destacan que si el ambiente de trabajo no provee musicalización preestablecida, puede optarse por encender la radio o elegir música a través de las alternativas que ofrece cualquier computadora conectada a la World Wide Web, desde iTunes a Spotify y desde las redes $\mathrm{P} 2 \mathrm{P}$ a SoundCloud ${ }^{\mathbf{5}}$.

Lo que puede observarse en la descripción de los casos citados es la convivencia de rasgos propios del networking junto a la permanencia de otros característicos del broadcasting y la convergencia de procesos de mediatización sonora correspondientes a distintas temporalidades. Mientras en 2014 el disco en formato físico aún constituye cerca de la mitad de los ingresos dela industria

4 Bertetti (2009, p. 72) se refiere a la crisis del "álbum musical" como "texto discográfico", conformado tanto por la música como por la tapa, el packaging, la gráfica, el soporte y demás elementos del objeto "disco". Su observación parte de los datos de la Federación Internacional de la Industria Fonográfica, que indican que en 2007 las descargas legales aumentaron un 53\% respecto a 2006. En cambio, en el año 2014, aunque las descargas siguen siendo la principal fuente de ingresos digitales, éstas cayeron un $8 \%$, al igual quelas ventas físicas, mientras creceel streaming (IFPI, 2015).

5 Esto es, desde las descargas a la difusión por flujo continuo y desde la transferencia de archivos entre pares a la posibilidad de introducir comentarios en la onda sonora de una canción o componer y compartir producciones propias. 
musical frente a las descargas, la posibilidad de "encender" la radio se presenta como una delas opciones mencionadas parala sonorización del espaciolaboral ante la música digital.

Asimismo, en los modos de recepción y consumo musical ejemplificados por Yúdice predominan aquellos constituidos en el período broadcasting, conformado en base a los medios sonoros. El pasaje de la musicalización del cine con orquestas en vivo a la sincronización con discos, antes de la impresión del sonido en la película, y la distribución de música por línea telefónica a empresas desde la Corporación Muzak fueron novedades desarrolladas entre 1920 y 1930. La permanencia de estos fenómenos y su convivencia con los iPods desde 2001 requiere ser indagada, por lo tanto, en la especificidad de sus rasgos novedosos frente a la caracterización de una música cada vez más ubicua.

Es en este entramado definido por Fernández (2014) como postbroadcasting donde se ubica la conformación de Spotify junto a las plataformas de streaming musical. Comprender su inscripción implica advertir que un fenómeno nuevo en la mediatización es generado y, a la vez, que el mimo implica dos movimientos convergentes pero opuestos de acumulación y transformación (Fernández,2008b). Para que un fenómeno novedoso se consolide como social debe recuperar rasgos de fenómenos previos. Pero de igual modo, para que ese fenómeno pueda ser considerado como novedoso deben cambiar usos y costumbres discursivas previas.

Si bien estos movimientos y las causas de la novedad mediática suelen restringirse a la innovación tecnológica, su despliegue puede establecerse tanto en los dispositivos técnicos, como en los géneros y estilos, y en las prácticas sociales y metadiscursivas que acompañan los usos de los medios. Es en la articulación de las historias particulares de estas dimensiones de relativa independencia bajo un cierto estilo de época, que la aparición de un fenómeno mediático genera, a su vez, efectos sobre la propia época ${ }^{6}$.

En función de adoptar este modelo de análisis de carácter descriptivo avanzaremos sobre la definición de cada una de las tres series en torno Spotify y a la emergencia de los servicios de streaming en el campo de la mediatización musical. Reparar sobre el carácter multidimensional de su construcción discursiva en un momento de convivencia conflictiva de distintas lógicas mediáticas permitirá sistematizar y distinguir qué rasgos permanecen y cuáles resultan novedosos en el marcoc de las nuevas articulaciones.

6 "La aparición de un fenómeno discursino mediático depende de que -en el contexto y con el impulso, conflictivos ambos, de un cierto estilo de época- se articulen elementos de las historias particulares (de las tecnologías utilizables en comunicación, los géneros y estilos discursivos y las costumbre de intercambio comunicacional disponibles) generando efectos, a su vez, en el propio estilo de época" (Fernández, 2008b, p.14). 


\section{DISPOSITIVO FONOGRÁFICO, INTERFAZ, PORTABILIDAD Y MOVILIDAD}

Con la emergencia del dispositivo fonográfico a fines del siglo XIX comenzó el proceso de mediatización sonora que derivó en la consolidación de la industria musical hacia 1920. Este proceso posibilitó la captura de sonidos generados por fuentes, su conversión en señales eléctricas, la fijación mediante diferentes soportes y la reconversión en señal audible para su emisión y recepción ${ }^{7}$. Tras más de un siglo y diversos estadios, las plataformas de música vía streaming se inscriben al final de ese proceso en el período iniciado en 1995 con el lanzamiento del formato mp3. En ese mismo año, se registraron los primeros usos de la difusión por flujo continuo en Internet, pero sus características no correspondieron al dispositivo fonográfico sino al radiofónico. Entre los primeros hitos, se registraron las transmisiones en directo de conciertos y eventos deportivos al modo broadcasting propio de los orígenes de la radio ${ }^{8}$. Sólo posteriormente la posibilidad de la reproducción de audio en simultaneidad a la descarga fue considerada como forma de acceso a archivos bajo demanda al modo de Spotify.

No obstante, si consideramos los orígenes del streaming antes de Internet, sus gérmenes se encuentran en relación al fonografismo y la mediatización específica de lo musical. La Corporación Muzak, al utilizar el sistema de transmisión y distribución a través de las líneas eléctricas patentado por George O. Squier en 1922, sentó las bases de la musicalización por flujo continuo. Las plataformas de streaming musical responden a una continuidad de esta tecnología, así como también de sus primeros usos, generando principalmente cambios en la distribución o delivery musical tanto respecto a la industria discográfica tradicional como en relación a las descargas. A ello se suman rasgos propios de la interfaz junto a la portabilidad y la movilidad.

A diferencia de la materialidad textual que acompaña al objeto disco y que fuera disuelta a partir de las descargas en términos de Bertetti (2009), los sitios musicales nos sitúan frente a distintas interfaces que comprenden a los modos de interacción que propone cada aplicación. Allí el carácter multimedial del fonografismo adquiere un grado distinto de visualidad en su acompañamiento por imágenes y propone nuevas formas de contacto.

Tanto en la versión de "Reproductor Web" como en la aplicación mobile, Spotify construye un espacio interactivo centrado en la exploración. "Explorar" se presenta como la acción destacada a ejecutar por el usuario, por sobre "Buscar", "Seguir" y "Reproducir". Esta actividad retoma una de las primeras

7 La noción de dispositivo técnico en los medios refiere al herramental tecnológico que posibilita variaciones en diversas dimensiones de la interacción comunicacional que "modalizan" el intercambio discursivo cuando éste no se realiza cara a cara. Todo medio de comunicación se define a partir de un dispositivo técnico o conjunto de ellos más sus prácticas sociales vinculadas (Fernández, 2008a).

8 Entre otros casos, en 1995 la empresa RealNetworks, una de las primeras proveedoras de servicios de streaming y creadora del formato RealAudio, transmitió en directo el audio del juego de baseball entre los New York Yankees y los Seattle Mariners. 
denominaciones que recibieron las aplicaciones informáticas para gestión y administración de $\operatorname{archivos}^{9}$, rasgo que puede encuadrarse en la utilización que las "interfaces culturales" hacen de las "interfaces de usuario generalista", al basarse en viejas metáforas y gramáticas de funcionamiento (Manovich, 2005, p. 140).

En esta línea, Spotify mantiene el uso de elementos de una semántica estándar a través del menú jerárquico, las ventanas de selección y la entrada de datos por comandos para la búsqueda pero, como propio dela interfaz cultural, oculta los hipervínculos que señalan qué objetos pueden ser operados. Tal es el caso de la opción de reproducción que subyace a la imagen que identifica a cada playlist. En cuanto a los íconos, estos son recuperados como estilo gráfico para diferenciar las opciones de "Géneros y Estados de ánimo" mediante ilustraciones simples y monocromáticas que construyen en modo dominante operaciones de metonimia respecto a su descripción textual ${ }^{\mathbf{1 0}}$.

La acción de "Explorar" se refuerza con otras como "Descubrir" y "Sorpréndete con música nueva". A diferencia de la opción "Buscar" mediante la introducción de criterios de búsqueda por texto, que opera al modo de los sitios de descargas bajo elecciones preestablecidas, la exploración invita al usuario acercarse a un saber que desconoce. La propuesta es realizada en forma jerárquica por Spotify bajo distintas modalidades como "Descubrimiento semanal de Spotify", o en forma horizontal por otros usuarios a los que se puede "Seguir" o con quienes se puede compartir playlists.

La aplicación mobile, por su parte, se basa en la conjunción de dispositivos que permiten la movilidad de los receptores y la ubicuidad de la información gracias al acceso a Internet. Luego de la movilidad de la información electrónica, que permitió la transmisión de música grabada, Scolari y Logan (2014) destacan la aparición de estas nuevas formas de portabilidad a partir de la digitalización. Mientras el walkman y posteriormente el reproductor de mp3 posibilitaron la escucha musical en cualquier lugar, Internet, los smartphones, las tablets y la tecnología Wi-Fi brindaron acceso ubicuo a la información.

Desde la misma mirada histórica sobre la movilidad y la portabilidad, Gopinath y Stanyek (2014) identifican la emergencia del sustantivo mobile music con el walkman en 1979 pero se remontan a las Victrolas, los Gramófonos portables y las radios para situar en la década del '20 el origen de conceptos que, como el de ubicuidad y "en todo momento, en cualquier parte", caracterizan hoy a la música móvil. Para comprender cuál es la inscripción específica de las plataformas de streaming sobre estas nociones avanzaremos en su articulación en el plano discursivo y de las prácticas sociales.

9 ElExplorador de Archivos de Windows lanzado en 1995 como componente central del sistema operativo Windows, popularizó el modo de gestión espacial basado en íconos y en la organización de diferentes ventanas. En la versión en inglés de Spotify se utiliza el término browse, en este caso sobre la metáfora de navegación de los Navegadores Web.

10 Por ejemplo: dos copas llenas chocando figuran la categoría "Fiesta”, un sillón la de "Relax" y parte de una trompeta la de "Jazz". Vea figura 1. 


\section{DEL ACCESO A LA ORGANIZACIÓN DE LA OFERTA: GÉNEROS, MOMENTOS Y ESTADOS DE ÁNIMO}

La revolución del acceso de los actores individuales a la discursividad mediática ha sido identificada por Eliseo Verón (2013) como el principal efecto de Internet sobre la historia de las mediatizaciones ${ }^{11}$. En el marco de las transformaciones del broadcasting al networking en la industria fonográfica, la digitalización, el formato mp3 y las descargas han evidenciado, en efecto, cambios sobre la accesibilidad musical. En línea con lo que venimos desarrollando, puede agregarse que las tecnologías wi-fi, la computación en la nube, los teléfonos inteligentes y las tablets han profundizado el carácter ubicuo del acceso. No obstante, reparar en la ubicuidad musical propiciada por las plataformas de streaming sólo ilumina un aspecto parcial.

La posibilidad de la escucha instantánea en cualquier momento y lugar es ofrecida desde distintas plataformas que construyen su propuesta discursiva institucional. Una vez conformado un amplio archivo musical mediante el acuerdo de licencias y tras el acceso ya alcanzado socialmente a partir de la práctica de las descargas, los servicios de streaming bajo demanda buscan diferenciarse a partir de la organización de la oferta musical basada en criterios de selección de playlists y recomendaciones.

Elcontenido musicalysuorganización constituyen rasgos propiosdelmediofonográfico como mediolleno ${ }^{12}$. Desde 1889, los primeros catálogosdelascompañías fonográficas promocionaron recitaciones, silbidos artísticos, grabaciones vocalese instrumentales, ejecuciones de bandas militares, marchas, valses y polkas ${ }^{13}$. Fue hacia 1920, con el desarrollo del modelo industrial, quela música devino en el material sonorodeeminentegrabaciónyseimpusolacatalogación porgéneros, encuyo marco el tango y el jazz se destacaron en su consolidación masiva (Fernández, 2008b).

Parte de este movimiento puede explicarse a partir de la afirmación de que todo nuevo medio suele postergar la adscripción de sus productos a moldes de género, nuevos o ya existentes en la cultura, en lo que Steimberg (1993) denomina el momento macluhaniano de la fascinación por la ruptura tecnológica y por su impacto en el intercambio social. Partiendo de su conceptualización, la noción de género aquí adoptada refiere a clases de objetos culturales que presentan diferencias sistemáticas entre sí y que en su recurrencia histórica instituyen condiciones de previsibilidad.

El catálogo musical ofrecido por Spotify presenta una hibridación de estos sistemas clasificatorios. Su principal categoría, denominada "Géneros y

11 Enfatizando en el carácter World Wide de la Web, Verón postula que "la WWW comporta una mutación en las condiciones de acceso de los actores individuales a la discursividad mediática, produciendo transformaciones inéditas en las condiciones de circulación” (2013, p. 281).

12 "Que propone puro contenido y pura recepción, con un intercambio discursivo desplazado en el tiempo, y desnivel con respecto a la instancia de emisión” (Fernández, 2008b, p. 17).

13 Explica Gitelman (2006) que la selección del repertorio se adjudicaba a la imperfección técnica, ya que los silbidos y los tenores grababan bien, pero no las sopranos. 
estados de ánimo", diferencia sus componentes en: "Latina", "Fiesta”, "Estados de ánimo", "Pop", “Ejercicio", "Relajación”, "Rock”, "Concentración”, "Décadas", "Viajes”, "Para comer", "Para dormir", "Reggae”, Religioso", “Jazz", "Folk \& Americana", "Rythim \& Blues", "Metal”, "Infantil”, “Country”, "Blues", "Funk", "Punk" "Trending” y "Humor". Mediante el diseño iconográfico, se homologan en una misma serie sistemas disímiles que corresponden a géneros musicales y clasificaciones de la industria discográfica, estados de ánimo, actividades y, con la etiqueta de humor, se categoriza incluso sketches de comedia y stand-up.

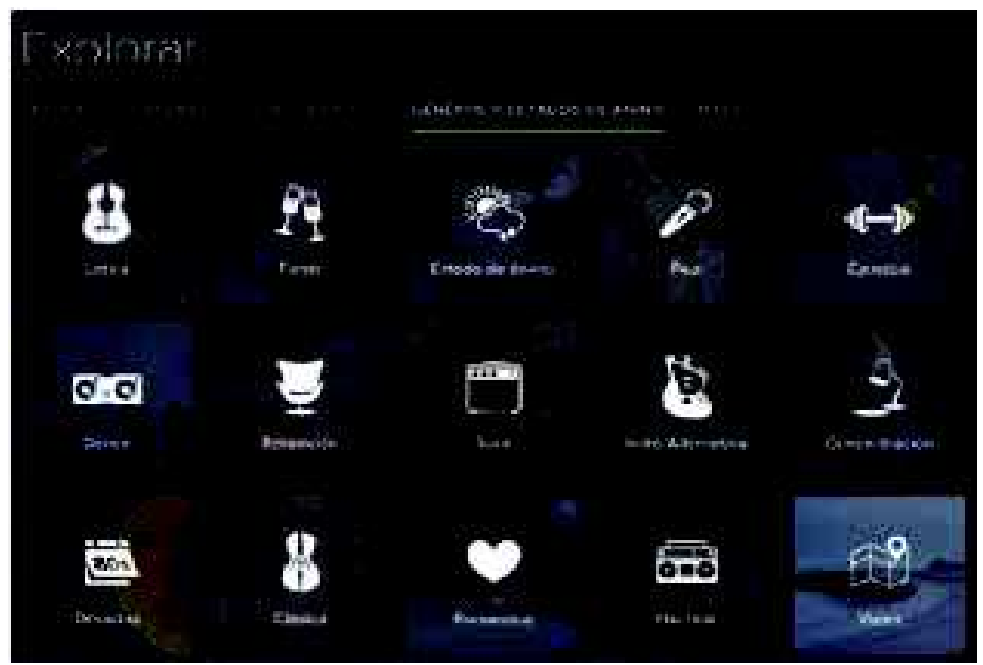

Figura 1. Spotify.

Explorar: géneros y

estados de ánimo.

Todos los casos incluyen listas de reproducción predeterminadas por Spotify para el mercado global o local que combinan singles de diferentes discos y artistas, y que el usuario puede "Seguir". Sólo aquellos que refieren a la clasificación por géneros compartida por las compañías discográficas como "Pop", "Dance”, "Rock", “Reggae", “Jazz", "Folk \& Americana”, "R\&B”, "Metal”, "Country”, "Blues", "Funk", "Punk" y "Latina”, presentan además de las playlists a "Artistas", "Nuevos Lanzamientos", "Eventos próximos" en la ciudad cercana al usuario y "Álbumes". Con las mismas opciones pero sumando "Country" y "Club/House", Spotify ofrece la opción "Radio" con "Emisoras por género" y "Emisoras Recomendadas" que generan listas por artistas relacionados ${ }^{14}$.

Esta catalogación por géneros, característica de la industria musical broadcasting, se ve equiparada a otras clasificaciones que responden a distintas etapas de la mediatización musical. En relación al "Humor", su convivencia con las grabaciones musicales no resulta novedosa sino que se remonta a los primeros discos de comienzos de siglo XX que incluían obras teatrales promocionadas en los avisos con la imagen del oyente individual riendo frente al fonógrafo. La

14 La compleja utilización del concepto de radio por parte de las plataformas de streaming excede los límites de este texto, pero cabe destacar que aunque algunas emisoras radiales han construido su programación e identidad institucional en función a la especialización en géneros musicales, nunca existió la radio como exclusiva transmisión de flujo musical (Fernández, 2008a). 
noción de mood music, por su parte, fue empleada a comienzos de 1920, cuando Thomas A. Edison patrocinó una investigación con el objetivo de clasificar los efectos de la música sobre los estados de ánimo ${ }^{15}$. Si bien indagaba sobre una escucha atenta y en el ámbito hogareño, aquel interés sentó las bases de los estudios sobre la música funcional (Grajeda, 2013).

Su continuidad fue asumida en la década del 30 por la Corporación Muzak en relación a la música para acompañar una actividad. Aunque originalmente consistió en la producción de música bajo ciertos parámetros para ser distribuida a empresas y fábricas ${ }^{\mathbf{1 6}}$, los seguidores del modelo Muzakabandonaronla producción musical por la programación en base a grabaciones del mercado discográfico (Martí, 2002). Esta variante esla que continúa Spotify al basarseenla organización y distribución de la música de la industria según criterios de funcionalidad.

Lo que estos modos de clasificación de listas de reproducción expresan es la tendencia a la curaduría y a la recomendación como forma creciente de diferenciación entre las plataformas de streaming. Junto a la incursión en la propia producción de grabaciones en vivo como las Spotify sessions y las listas de temas seleccionadas por Spotify como institución, se difunden las playlist curadas por personajes públicos como artistas, políticos y deportistas ${ }^{17}$. A su vez, a diferencia de la argumentación sobre la calidad de sonido adoptada por sitios como Tidal, las discográficas y las empresas de streaming evidencian un aumento del interés en las recomendaciones inteligentes de música ${ }^{\mathbf{1 8}}$.

En Spotify, esta inteligencia se basa en una oferta de playlists no estática sino generada a partir de las elecciones que conforman el perfil del usuario ${ }^{19}$ y de la sugerencia según el momento del día y/o de la semana. La página de inicio "Descripción General” destaca listas de reproducción bajo títulos como: "Así suenan las noches..., “¡Ponle música a tu mediodía!”, “\#juevesdeantaño” y “iPor fin viernes!”. La propuesta de escucha personalizada e individual se refuerza en las imágenes fijas, fotográficas y a color producidas por Spotify con su logo para cada lista, en tanto predominan las imágenes individuales de jóvenes en un estado relacionado con la descripción del título y del epígrafe. Ambos aspectos, de temporalidad y visualidad, se vinculan asimismo en las prácticas de recepción musical.

15 La investigación se desarrolló durante dos años y entre sus resultados derivó en un paper en 1921, que identificó 589 grabaciones según sus efectos sobre el oyente (Grajeda, 2013).

16 La Muzak producía una programación musical con intervalos regulares de pausas según las horas de trabajo de menor rendimiento para reequilibrarlas con la estimulación sonora a través de parámetros basados en el tempo, ritmo, instrumentación y tamaño de la orquesta (Martí, 2002).

17 Entre los casos más relevantes se encuentran The President's Summer Playlist, de Barak Obama, y la Playlist para entrenar, de Floyd Mayweather.

18 En 2014, Daniel Ek, fundador y director ejecutivo de Spotify, luego de que la compañía adquiriera al proveedor de datos musicales The Echo Nest, manifestó el objetivo de "desarrollar la 'mejor plataforma de inteligencia musical del planeta', que combine la habilidad humana con la selección de contenidos de las redes sociales ylos algoritmos” (IFPI, 2015, p. 20).

19 Spotify presenta, asimismo, la conexión con cuentas de Facebook y permite hacer scrobbling con LastFM. Esta modalidad sincroniza el monitoreo de la música escuchada en ambas plataformas para ofrecer recomendaciones a partir de ella. 


\section{ESCUCHA MUSICAL EN CUALQUIER LUGAR, EN TODO MOMENTO}

"Déjatellevar por el momento. Puedes musicalizar toda tu vida con Spotify. Sea lo que sea que estés haciendo o sintiendo, nosotros tenemos la música perfecta para hacer de lo bueno algo todavía mejor"20. Este texto, destacado en la página principal del sitio Web de Spotify Argentina, permiteidentificar algunas de las principales prácticas de escucha musical promovidas por la plataforma. Desde un "nosotros" exclusivo proveedor de la oferta musical se construye el "Tú" de la escucha individual como forma de acompañamiento a la actividad social. La música como banda sonora es reproducida en continuo a partir de la elección instantánea respecto al sentir de cada momento desde cualquier lugar en base a opciones personalizadas y preestablecidas para el oyente.

La posibilidad técnica de la ubicuidad y la portabilidad de la música digital es apropiada a nivel discursivo en relación a prácticas sociales vinculadasalos modos de elección y escucha musical, sus espacios y temporalidades. En la confluencia de la comunicación ubicua, con servicios diseñados de acuerdo a la localización del usuario, y junto a la integración de distintos modelos comunicacionales, Spotify se enmarca en la mCommunication como "práctica social de producción y consumo de contenidos y apropiación de tecnologías articulada a través de la difusión masiva de dispositivos Wi-Fi multifuncionales" (Scolari y Logan, 2014, p. 71).

Partiendo de las prácticas de los oyentes, el acceso a la plataforma web o mobile constituye sólo el comienzo del proceso de interacción comunicacional. Junto con el despliegue de imágenes visuales, el "déjate llevar" en la elección musical instantánea es promovida por la exploración y el descubrimiento. Estas opciones, ofrecidas como playlists personalizadas, se ven ponderadas frente a la búsqueda direccionada por el usuario sobre criterios predefinidos al modo de la compra de discos físicos y del downloading. El impacto de este factor ha sido mesurado en estudios que sostienen el aumento de la variedad en el consumo de géneros musicales a partir de la digitalización en la denominada "Era shuffle" (Havas, 2015). En Argentina, por ejemplo, se destaca el predominio del perfil de oyente ávido a la "exploración" de canciones, artistas, géneros y lugares nuevos relacionados con la música ${ }^{21}$.

La propagación de estas prácticas permite tensionar la caracterización realizada por Henry Jenkins (2006, p. 215) respecto a los medios masivos como medios de empuje "cuyos mensajes salen hacia el público tanto si éste los busca como si no" y el medio de atracción "que sirve a quienes buscan activamente información sobre un determinado tema”. En el dejarse llevar por el flujo continuo de la lista de reproducción, se interpela a la predisposición del oyente a ser sorprendido por la oferta inteligente que Spotify le propone generar de acuerdo a sus preferencias.

20 En línea: https://www.spotify.com/ar

21 Estudio Fans.Passions. Brands de Havas Sports \& Entertainment sobre 18.000 encuestados en 17 países, un 56\% escucha al menos 10 géneros musicales por día. 
Este rasgo se ve enfatizado en la versión mobile gratuita en la cual la reproducción es sólo aleatoria o shuffle, no permite saltos en las listas de temas, y se define por las recomendaciones según el momento del día y de la semana presentadas en la portada: "Desde que te despiertas hasta el fin dela noche, la nueva página de inicio Now te espera para ofrecerte la música perfecta. Y como ahora Spotify reconoce lo que te gusta, estarás $100 \%$ seguro de escuchar la música adecuada, seleccionada por expertos internos y desde tu colección personal"22.

Mientras la selección musical puede ser delegada alos "expertos", los modos predominantes de escucha propuestos se vinculan a las prácticas de recepción características de la música funcional o ambiental. La música oída pero no escuchada es aquella que se presenta como fondo de la acción y acompañamiento de otra actividad. Junto a las opciones de música para "Ejercicio", "Relajación", "Concentración", "Viajes", "Para comer”, "Para dormir”, la opción Running en la aplicación mobile exacerba la función de la escucha como acompañamiento en movilidad: "Spotify Running detecta tu ritmo y te pone música que coincida con tu paso" 23 .

En relación a la espacialidad, la oferta de programación en movimiento combina ubicuidad y portabilidad. La escucha en el hogar es sólo una opción que contrasta con los usos en el comienzo del fonografismo en relación al slogan "Opera at Home" o "El teatro en casa" popularizado por la Victor Talking Machine Company. Aquella novedad de escuchar a los artistas musicales y de la comedia al interior del hogar apropiada socialmente en forma dominante aún frente a la emergencia de gramófonos portables, se ve invertida por la preponderancia del uso de Spotify desde smartphones y tablets. Según las estadísticas de 2015, más de la mitad de los 60 millones de usuarios activos de Spotify a nivel global escuchan música en streaming a través de celulares: un $42 \%$ accede al servicio desde los teléfonos inteligentes y un 10\% lo hace desde tablets (IFPI, 2015).

Finalmente, en relación a la temporalidad, además de modificar la sugerencia de playlists según el momento del día, Spotify organiza los tiempos de las novedades a nivel individual y colectivo. Los descubrimientos semanales personalizados para cada usuario se presentan los lunes y los nuevos lanzamientos los días viernes, en forma coordinada con el conjunto de las discográficas multinacionales y los sellos independientes de todo el mundo. Por primera vez en la historia de la industria, en febrero de 2015 se llegó al acuerdo global de lanzar las novedades en forma sincronizada según la hora local de cada mercado (IFPI, 2015). Esta regulación del tiempo social del consumo musical en las redes, adoptado por Spotify, corresponde a un funcionamiento centralizado propio del modelo broadcasting.

22 En línea: https://news.spotify.com/sv/2015/05

23 En línea: https://www.spotify.com/ar/running 


\section{CONCLUSIONES}

En el Informe sobre la música digital, Edgar Berger, Presidente y Director Ejecutivo de la División Internacional de Sony Music Entertainment, describe el estado de situación: "La industria de la música está atravesando al mismo tiempo la transición del formato físico al formato digital, de la computadora a los dispositivos móviles y de las descargas al streaming" (IFPI, 2015, p. 7). En este momento en el cual broadcasting y networking conviven en tensión, Spotify se presenta como una de las principales plataformas de servicios de música bajo demanda donde se apoya la industria para la conformación de un nuevo estadio.

La novedad se genera a partir de la combinación de distintas lógicas desarrolladas en forma central o tangencial en la historia de la mediatización musical. Las series de los dispositivos técnicos, los géneros y estilos discursivos, y las prácticas sociales de intercambio, se articulan a su vez en la conformación de procesos comunicacionales que exceden a la innovación tecnológica o a la adopción de un modelo económico industrial sustentable.

A nivel del dispositivo, la portabilidad, la movilidad y las bases técnicas del streaming no resultan novedosas sino que adquieren nuevas configuraciones junto a la ubicuidad del acceso promovido por Internet, las redes wi-fi y la expansión del uso social de smartphones y tablets. Las implicancias en la instantaneidad del acceso y la elección musical, sin el requerimiento de espera necesario en las descargas o en los tiempos de adquisición y reproducción de los discos físicos, generaron cambios en la temporalidad del consumo musical que se sumaron a la disponibilidad del vasto archivo musical alcanzado a partir de la digitalización.

Sin embargo, el slogan de Spotify ("Música para todos") no logra abarcar las especificidades que la plataforma presenta en su construcción discursiva y respecto a las prácticas de escucha. Spotify establece cambios respecto a la clasificación musical en la hibridación de sistemas. La organización de su archivo equipara el sistema de géneros musicales utilizado por los sellos discográficos como criterio de catalogación, con la música ofrecida como acompañamiento para los estados de ánimo y la realización de actividades, junto con grabaciones humorísticas.

Las listas de reproducción se convierten, bajo estos criterios, en el formato productivo de la industria musical digital en Spotify, provocando un nuevo embate a la unidad textual del disco. La figura del curador como experto capaz de seleccionar la música adecuada en base a recomendaciones algorítmicas, saberes profesionales o culturales, exime al oyente de la búsqueda proactiva, al tiempo que lo convoca a ejercer el rol de curador de listas para otros usuarios.

En la propuesta de musicalización ubicua de Spotify, el recorrido en paralelo a la industria fonográfica realizado por la Muzak y la música ambiental, 
desde su gestación común en las primeras décadas del siglo XX, establece un nuevo cruce. La música como flujo promueve la escucha desatenta del oyente mientras éste desarrolla otra actividad, como práctica socialmente aprendida con el medio radiofónico. En el postbroadcasting, la banda sonora del sentir y el hacer individual se combina con lógicas centralizadas que regulan la oferta y son reguladas, a su vez, por el ritmo de vida social. En tiempos de usuarios participativos, el oyente ubicuo de Spotify es invitado a explorar y descubrir música o simplemente a dejarse llevar.

\section{REFERENCIAS}

Bertetti, P. (2009). En Carlón, M. y Scolari, C. (Eds.). El fin de los medios masivos. El comienzo de un debate. Buenos Aires: La Crujía.

Boschi, E., Kassabian, A. \& García Quiñones, M. (2013). Introduction: A Day in the Life of a Ubiquitous Musics Listener, en Ubiquitous Musics: The EverydaySounds That We Don't Always Notice. Farnham: Ashgate.

Fernández,J.L.(2014).Periodizaciones deidasyvueltas entre mediatizacionesymúsicas, en Postbroadcasting. Innovación en la industria musical. Buenos Aires: La Crujía.

Fernández, J. L. (2008a). La construcción de lo radiofónico: modos de producción de la novedad discursiva, en La construcción de lo radiofónico. Buenos Aires: La Crujía.

Fernández,J.L.(2008b). Acumulación y transformación en el surgimiento delos medios de sonido. L.I.S. Letra, imagen sonido. Ciudad mediatizada, 11 (5). Buenos Aires: UBACyT S094-FCS-UBA.

Gitelman, L. (2006). Always already new: media, history and the data of culture. Cambridge: MIT Press.

Gopinath, S. \& Stanyek, J. (2014). Anytime, anywhere? An introduction to devices, markets and theories of mobile music, en The Oxford Handbook of Music Mobile Studies, vol. 1. Oxford: Oxford University Press.

Grajeda, T. (2013). Early Mood Music: Edison's phonography, american modernity and the instrumentalization of listening, en Ubiquitous Musics: The Everyday Sounds That We Don't Always Notice. Farnham: Ashgate. 
Havas Media (2015). The Shuffle Age: Global Music Fans Unplugged. Recuperado: 25 de septiembre de 2015. En línea: http://www.havasmedia.com/press/pressreleases/2015/the-shuffle-age-global-

IFPI (2015). Informe sobre la música digital. En línea: en http://ifpi.org/downloads/ Digital-Music-Report-2015.pdf

Jenkins, H. (2008). Photoshop para la democracia: La nueva relación entre política y cultura popular, en Convergence Culture. La cultura de la convergencia de los medios de comunicación. Barcelona: Paidós Ibérica.

Manovich, L. (2005). La interfaz, en El lenguaje de los nuevos medios de comunicación. Barcelona: Paidós.

Martí, J. (2002). Músicas invisibles: la música ambiental como objeto de reflexión, TRANS-Revista Transcultural de Música 6, artículo 13. Recuperado: 25 de septiembre de 2015. En línea: http://digital.csic.es/bitstream/10261/38548/1/ JMarti-2002-TRANS\%20

Scolari,C. \& Logan, R. (2014). El surgimiento dela comunicación móvil en el ecosistema mediático, L.I.S. Letra, imagen sonido. Ciudad mediatizada, 11 (5). Buenos Aires: UBACYT S094-FCS-UBA.

Steimberg, O. (1993). Proposiciones sobre el género, en Semiótica de los medios masivos. Buenos Aires: Atuel.

Verón, E. (2013). La revolución del acceso, en La Semiosis Social 2. Buenos Aires: Paidós

Yúdice, G. (2007). Nuevas tecnologías, música y experiencia. Barcelona: Gedisa.

\section{JIMENA JAUREGU!}

Becaria UBACyT de Doctorado en Ciencias Sociales. Licenciada y Profesora en Ciencias de la Comunicación (UBA). Docente de Semiótica de los Géneros Contemporáneos (FSOC-UBA). Integra el equipo editorial de la revista Letra. Imagen. Sonido. Ciudad Mediatizada. Desde sus inicios en la investigación como becaria Estímulo se ha dedicado a la historia del tango en los medios. Ha publicado diversos trabajos en congresos, libros y revistas académicas. En 2012 obtuvo la Beca Julio Palacio de la Biblioteca Nacional.

E-mail:jimenajauregui@gmail.com 